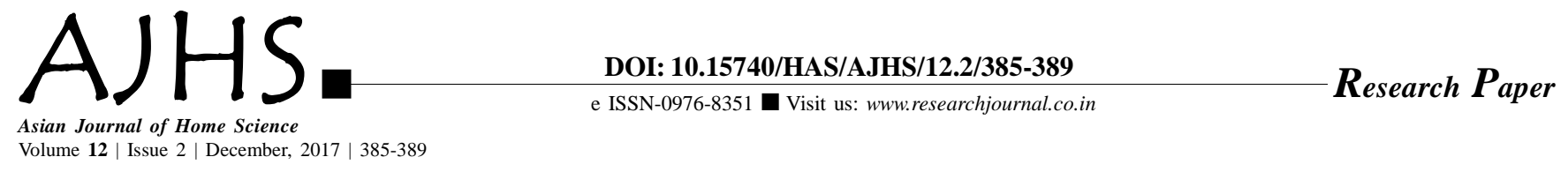

\title{
Musculoskeletal discomfort perceived by perishable good sellers in hilly areas
}

\section{RANIMA SAIKIA}

Received: 24.04.2017; Revised: 27.09.2017; Accepted: 13.10.2017

Author for Correspondence :

RANIMA SAIKIA

College of Home Science, Central

Agricultural University, TURA (MEGHALAYA) INDIA
ABSTRACT : The study was conducted to find out the musculoskeletal discomfort perceived by vegetable and fruit sellers while performing the activities to complete the whole process of selling from procuring the goods till handing it over to the buyers. A total of 50 sellers within the age group of 18 to 50 years from West Garo Hills are considered for the study. Findings revealed that the respondent's involved in selling of vegetables and fruits felt discomfort ranging from moderate to severe. The perceiving of moderate to severe pain in different parts of the body may lead to musculoskeletal disorder. Hence, for ergonomic intervention to prevent musculoskeletal disorder at the early stage database related to perceived discomfort is essential.

KEY WORDS: Musculoskeletal problems, Body map, Pain, Upper body parts, Lower body parts

- HOW TO CITE THIS PAPER : Saikia, Ranima (2017). Musculoskeletal discomfort perceived by perishable good sellers in hilly areas. Asian J. Home Sci., 12 (2) : 385-389, DOI: 10.15740/HAS/AJHS/ 12.2/385-389. 